\title{
PREPARO DAS SEMENTES DE CAFÉ PARA AVALIAÇÃO DA VIABILIDADE PELO TESTE DE TETRAZÓLIO ${ }^{1}$
}

\author{
ALINE DA CONSOLAÇÃO SAMPAIO CLEMENTE², MARIA LAENE MOREIRA DE CARVALHO³, \\ RENATO MENDES GUIMARÃES ${ }^{3}$, WALMES MARQUES ZEVIANI ${ }^{4}$
}

\begin{abstract}
RESUMO - O teste de tetrazólio (TZ) é uma alternativa para avaliação rápida da viabilidade de sementes já adotada para a comercialização de sementes de café. Um dos entraves para a utilização do teste é a dificuldade na extração do endocarpo que demanda tempo e mão de obra especializada. A utilização de hipoclorito de sódio é recomendada para extração do endocarpo de sementes de café para acelerar o processo de germinação, no entanto essa metodologia ainda não foi testada na realização do teste de tetrazólio. Sementes de café de quatro lotes de duas cultivares foram submetidas a quatro metodologias para a realização do teste: extração manual ou utilização de hipoclorito de sódio (200 $\mathrm{mL}$ de $\mathrm{NaClO}$ a 5\%) para remoção do pergaminho e períodos de embebição das sementes em água (36 e 48 horas) para a retirada dos embriões. Os resultados de viabilidade pelo TZ foram comparados com os de germinação das sementes com diferentes teores de água. O uso do $\mathrm{NaClO}$ na concentração de $5 \%$ por 6 horas de embebição não é eficiente para a retirada do pergaminho e afeta negativamente os resultados do TZ em semente de café com teor de água abaixo de $25 \%$. O período de embebição de sementes de café em água por 48 horas na fase de preparo, para a realização do TZ, facilita a extração dos embriões, não afetando os resultados do teste.
\end{abstract}

Termos para indexação: hipoclorito de sódio, Coffea arabica, embebição.

\section{PREPARATION OF COFFEE SEEDS TO ASSESS VIABILITY USING THE TETRAZOLIUM TEST}

\begin{abstract}
The tetrazolium test (TZ) is a rapid alternative for evaluating seed viability and has been adopted for the commercialization of coffee seeds. One of the barriers to using this test is the difficulty of extracting the parchment, which requires time and specialized labor. The use of sodium hypochlorite has been recommended for parchment extraction in coffee seeds but this method has not been tested for the TZ. Coffee seeds of four lots of two varieties were submitted to four methods in the test: manual extraction or use of sodium hypochlorite $(200 \mathrm{~mL} 5 \% \mathrm{NaClO})$ to remove the parchment and various periods for soaking seeds in water (36 to 48 hours), to remove the embryos. The results of the viability from the $\mathrm{TZ}$ were compared with those from the germination of seeds with different moisture contents. The use of $5 \% \mathrm{NaClO}$ with 6 hours of soaking is not effective in removing the parchment and adversely affects the results of the TZ in coffee seeds with a moisture content below $25 \%$. The imbibition period of coffee seeds in water for 48 hours in the preparation phase for the TZ, facilitates embryo extraction without affecting the test results.
\end{abstract}

Index Terms: sodium hypochlorite, Coffea arabica, imbibitions.

${ }^{1}$ Submetido em 12/04/2010. Aceito para publicação em 21/07/2010. Parte da Dissertação de Mestrado do primeiro autor apresentada a UFLA.

${ }^{2}$ Eng. Agr., Doutoranda do curso de Fitotecnia/Sementes, DAG/UFLA; C.P. 3037, 37200-000, Lavras, MG; alineagrolavras@gmail.com

${ }^{3}$ Profs. Drs. Departamento de Agricultura, DAG/UFLA; Caixa
Postal 3037, 37200-000, Lavras, MG; E-mail: mlaenemc@dag.ufla.br; E-mail: renatomg@dag.ufla.br

${ }^{4}$ Prof. Ms. Departamento de Estatística, UFPR, Caixa Postal 19081, CEP: 81531-990, Curitiba-PR, E-mail: walmes@ufpr.br 


\section{INTRODUÇÃO}

A importância econômica do café é indiscutível pelo fato de ser um dos mais valiosos produtos primários comercializados no mundo. O Brasil é o maior produtor mundial de café, responsável por $30 \%$ do mercado internacional, e o Estado de Minas Gerais responde por $48,6 \%$ da produção nacional (CONAB, 2009). A implantação da cultura do cafeeiro é feita por mudas, o que requer a utilização de sementes de alta qualidade. No entanto, pelas características relacionadas à sensibilidade à dessecação e lenta germinação, em torno de 30 dias, sob condições ideais de laboratório (Brasil, 2009), a avaliação da qualidade das sementes de lotes comerciais é dificultada.

Dentre os fatores relacionados com a germinação lenta e desuniforme das sementes, podem ser citados: maturação dos frutos e os processos de pós-colheita, como secagem e armazenamento (Pammenter e Berjak, 1999), a presença do espermoderma, também conhecido como "película prateada", devido conter inibidores naturais (Pereira et al., 2002) e a presença do endocarpo ou "pergaminho" que é considerada a principal característica responsável pelo atraso na germinação (Guimarães et al., 1998).

A remoção do endocarpo é uma alternativa usada para acelerar o processo de germinação e, consequentemente, a avaliação da qualidade das sementes de café (Guimarães, 1998). O endocarpo também conhecido como pergaminho, é um componente fibroso que representa de 28,7 a $38,8 \%$ da casca e é composto basicamente por $37 \%$ de celulose, $25 \%$ de hemicelulose e de 9,3 a $13,5 \%$ de lignina em base seca (Figueiredo et al., 2008; Barcelos et al., 2002) e tais componentes conferem ao pergaminho textura rígida e impermeabilidade ao tecido. $\mathrm{O}$ procedimento de remoção de pergaminho na avaliação da qualidade é trabalhoso e demanda muita mão de obra. Uma alternativa recentemente recomendada é a utilização do hipoclorito de sódio $(\mathrm{NaClO})$, técnica investigada por Meirelles et al. (2007), Lima (2008) e Sofiatti et al. (2009) com resultados satisfatórios. O uso da solução de hipoclorito de sódio, na concentração de $5,0 \%$ durante 6 horas, foi eficiente na degradação do pergaminho, observado por Meirelles et al. (2007). Já Sofiatti et al. (2009) observaram efeito negativo do hipoclorito para sementes com teor de água abaixo de $23 \%$, nos resultados do teste de germinação. Também Lima (2008) observou que a imersão de sementes de café com teor de água de 12, 16 e $20 \%$ em solução de hipoclorito nas concentrações 3, 4 e 5\% foi eficiente na remoção do pergaminho, acelerando a emergência de plântulas, em condições de viveiro.

$\mathrm{Na}$ indústria de celulose, o hipoclorito de sódio é utilizado para degradar a lignina (Hise, 1996). O ácido hipocloroso $\left(\mathrm{HOCl}^{-}\right)$, quando em contato com tecido orgânico age como um solvente, liberando cloro que, combinado com as proteínas do grupo amina, formam as cloraminas e juntamente com os íons hipoclorito $\left(\mathrm{OCl}^{-}\right)$ provocam a degradação e hidrólise de aminoácidos (Estrela et al., 2002). Devido a tais características, o ácido hipocloroso e os íons hipoclorito em contato com o endosperma e embrião podem afetar a qualidade fisiológica da semente.

A necessidade de remoção do pergaminho ocorre não só na realização do teste de germinação, mas também para outros testes como o teste de tetrazólio que vem sendo recomendado para a análise da viabilidade das sementes de café de acordo com a Portaria $n^{\circ} 482$, de 29 de novembro de 2001, do Instituto Mineiro de Agropecuário-IMA (2000).

O teste de tetrazólio baseia-se na atividade das enzimas desidrogenases, que reduzem o sal 2,3,5 trifenil cloreto de tetrazólio nos tecidos vivos da semente, pela reação de íons de hidrogênio que são transferidos para o referido sal (Delouche et al., 1976). A redução do sal ocorre apenas nas células vivas, resultando na formação do trifenilformazam, composto vermelho e indifusível que confere cor vermelha ao tecido vivo do embrião.

Para realização do teste de tetrazólio, além da retirada do pergaminho, há necessidade de extração do embrião que só pode ser feita em sementes umedecidas, já que o endosperma é um tecido muito duro. De acordo com as Regras para Análise de Sementes (Brasil, 2009); Dias e Silva (1986), deve-se embeber as sementes em água por 18 horas, em seguida fazer um corte na região onde se encontra o embrião, retirá-lo aderido ainda ao endosperma e embeber em solução de tetrazólio a $1 \%$ por mais 24 a 28 horas a $30{ }^{\circ} \mathrm{C}$. Já Vieira et al. (1998) relataram que o período de condicionamento das sementes varia em função da idade das mesmas, sendo indicado 18 a 24 horas para sementes recém-colhidas e 72 horas para sementes de safras anteriores, para que o embrião seja extraído diretamente. Em função das variações das metodologias indicadas, a pesquisa foi realizada com o objetivo de verificar o efeito do hipoclorito de sódio na retirada do endocarpo e do tempo de embebição para a extração do embrião de sementes de café, na realização do teste de tetrazólio. 


\section{MATERIAL E MÉTODOS}

O experimento foi conduzido no Laboratório Central de Sementes do Departamento de Agricultura da Universidade Federal de Lavras (UFLA), Minas Gerais. Foram utilizadas sementes de café recém colhidas na região de Lavras e Sul de Minas no ano agrícola de 2006/2007, as quais apresentavam diferentes teores de água e qualidade fisiológica. Foram utilizados 4 lotes das cultivares Mundo Novo 376-4 e Topázio MG 1190, avaliadas quanto à viabilidade pelo teste de tetrazólio e germinação.

No intuito de reduzir o tempo de execução do teste de tetrazólio, 4 metodologias foram avaliadas: 2 métodos para remoção dos pergaminhos e 2 períodos de embebição das sementes para retirada dos embriões. A remoção do pergaminho foi efetuada pela embebição de 400 sementes em solução de $200 \mathrm{~mL}$ de hipoclorito de sódio $(\mathrm{NaClO})$ a $5 \%$ por 6 horas à temperatura de $25{ }^{\circ} \mathrm{C}$ (Meireles et al. 2007). Este método de remoção foi comparado ao método convencional, em que o pergaminho foi retirado manualmente. Para a extração dos embriões, as sementes foram embebidas diretamente em água pelos períodos de 36 e 48 horas, à temperatura de $30^{\circ} \mathrm{C}$.

Teste de tetrazólio: foram utilizadas quatro repetições de 50 sementes para cada tratamento; após os períodos de embebição (36 e 48 horas), os embriões foram extraídos e mantidos em solução do antioxidante polivinilpirrolidona (PVP), desde o momento da sua extração dos endospermas até serem colocados na solução de tetrazólio. Ao término da extração dos embriões, estes foram lavados em água corrente com auxílio de uma peneira e embebidos em solução de tetrazólio $0,5 \%$ utilizando-se frascos escuros e submetidos à temperatura de $30^{\circ} \mathrm{C}$ por 2 horas. A análise da viabilidade dos embriões foi realizada com auxilio de uma lupa estereoscópica com aumento de 10 vezes para melhor visualização das estruturas internas e externas dos mesmos. Para isso, foi realizado um corte longitudinal ao meio dos embriões, os quais foram classificados em viáveis e inviáveis de acordo com a localização e extensão dos danos.

Teste de Germinação: foram utilizadas quatro repetições de 50 sementes sem pergaminhos (extraídos manualmente) para cada tratamento. A semeadura foi realizada em papel toalha tipo "germitest" (rolos de papel), umedecidos com água destilada na quantidade de duas vezes e meia a massa do papel seco, e colocadas para germinar a $30^{\circ} \mathrm{C}$, na presença de luz. A contagem final foi realizada no trigésimo dia após a semeadura, computando-se as plântulas normais em cada repetição, conforme os critérios estabelecidos pelas Regras para Análise de Sementes (Brasil, 2009).

Determinação do grau de umidade: realizada pelo método da estufa $105{ }^{\circ} \mathrm{C}$ durante 24 horas, utilizando 2 repetições para cada amostra conforme prescrições das Regras para Análise de Sementes (Brasil, 2009). Os resultados foram expressos em percentagem média por amostra.

Procedimentos estatísticos: o delineamento experimental utilizado foi o inteiramente casualizado, em esquema fatorial $4 \times 2 \times 2$ (quatro lotes, duas metodologias de extração do pergaminho e dois tempos de embebição), para cada cultivar isoladamente. Foi realizada a análise de variância dos dados e a comparação das médias foi feita pelo teste de Scott-Knott, a 5\% de probabilidade (características qualitativas) por meio do programa estatístico SISVAR ${ }^{\circledR}$ (Ferreira, 2000). As análises estatísticas para a comparação entre os resultados do teste de germinação e do teste de tetrazólio foram realizadas considerando distribuição binomial (com função de ligação canônica ou logística). A avaliação da diferença entre as metodologias e o efeito do tempo foi realizada por meio de contrastes e por redução na deviance residual do ajuste sequencial de modelos. $\mathrm{O}$ procedimento foi desenvolvido no software $\mathrm{R}$ ( $\mathrm{R}$ Development Core Team, 2008).

\section{RESULTADOS E DISCUSSÃO}

Os efeitos do hipoclorito de sódio, utilizado para extração do pergaminho de sementes de café, sobre a viabilidade avaliada pelo teste de tetrazólio variou em função dos lotes. Na Tabela 1 verificam-se valores inferiores de viabilidade das sementes quando se utilizou a solução de hipoclorito de sódio para a retirada do pergaminho, para a maioria dos lotes das duas cultivares estudadas. Apenas o lote 3 da cultivar Mundo Novo 376-4 e o lote 4 da cultivar Topázio MG 1190 não foram afetados negativamente pelo uso do hipoclorito de sódio para a extração do pergaminho. Vale ressaltar que, para estes lotes, o grau de umidade das sementes era superior a $26,5 \%$.

De acordo com Sofiatti et al. (2009), a solução de hipoclorito de sódio é eficiente na degradação e remoção de pergaminho em sementes de café quando estas apresentam grau de umidade acima de $23 \%$. Assim, provavelmente as sementes dos lotes com maiores graus 
de umidade não foram afetadas pelo cloro ativo devido à quantidade de água presente na semente, o que diminuiu a absorção dessa substância, minimizando os efeitos negativos na viabilidade dos embriões. O mesmo autor considerou que, quanto menor o grau de umidade inicial das sementes, maior é a absorção da solução de hipoclorito, o que ocasiona a degradação das membranas, menor seletividade, maior susceptibilidade à entrada de solutos e absorção mais rápida, causando a perda de viabilidade dessas sementes. Sofiatti et al. (2009) ainda sugeriram que a reação do hipoclorito de sódio pode ter ocasionado aumento na temperatura da solução de pré-embebição, favorecendo o aumento da absorção da solução. Bewley e Black (1982) afirmaram que a exposição de sementes ao hipoclorito de sódio por longos períodos pode provocar danos ao embrião.

TABELA 1. Médias de viabilidade (\%) e grau de umidade (U\%) de sementes de duas cultivares de café, submetidas a duas metodologias de extração do pergaminho (manual - $\mathrm{M}$ e $\mathrm{NaClO}$ - H).

\begin{tabular}{|c|c|c|c|c|c|c|}
\hline \multicolumn{7}{|c|}{ Cultivares } \\
\hline \multicolumn{4}{|c|}{ Mundo Novo 376-4 } & \multicolumn{3}{|c|}{ Topázio MG1190 } \\
\hline \multirow{2}{*}{ Lote } & \multirow{2}{*}{$\mathrm{U} \%$} & \multicolumn{2}{|c|}{ Mét. Extração do pergaminho } & \multirow{2}{*}{$\mathrm{U} \%$} & \multicolumn{2}{|c|}{ Mét. Extração do pergaminho } \\
\hline & & M & $\mathrm{H}$ & & M & $\mathrm{H}$ \\
\hline 1 & 21,0 & $79,75 \mathrm{Ad}^{1}$ & $76,25 \mathrm{Bd}$ & 17,5 & $87,50 \mathrm{Ab}$ & $83,25 \mathrm{Bc}$ \\
\hline 2 & 17,5 & $88,25 \mathrm{Ab}$ & $82,75 \mathrm{Bb}$ & 14,0 & $86,25 \mathrm{Ab}$ & $81,87 \mathrm{Bc}$ \\
\hline 3 & 29,5 & $90,00 \mathrm{Aa}$ & $90,00 \mathrm{Aa}$ & 16,0 & $89,37 \mathrm{Aa}$ & $85,12 \mathrm{Bb}$ \\
\hline 4 & 21,5 & $82,50 \mathrm{Ab}$ & $79,25 \mathrm{Bc}$ & 26,5 & $87,62 \mathrm{Ab}$ & $86,62 \mathrm{Aa}$ \\
\hline
\end{tabular}

${ }^{1}$ Letras maiúsculas nas linhas e minúsculas nas colunas, para cada cultivar, não diferem entre si pelo Teste Scott-Knott no nível nominal de significância de $5 \%$.

$\mathrm{Na}$ presente pesquisa, as sementes de café ficaram expostas por 6 horas à solução, o que pode ter provocado uma maior absorção de substâncias prejudiciais ao embrião, efeito constatado nos embriões que apresentavam maior descoloração na radícula.

Além do efeito negativo do hipoclorito de sódio na retirada do pergaminho de sementes com grau de umidade inferior a $25 \%$, vale ressaltar que no presente trabalho, a solução de hipoclorito de sódio utilizada não foi eficiente para a completa degradação do pergaminho, necessitando a retirada manual complementar dos pergaminhos remanescentes da maioria das sementes.

Pelos resultados do teste de tetrazólio referentes ao tempo de condicionamento (Tabela 2 ), pode-se observar que os dados de viabilidade das sementes pré-condicionadas no tempo de 48 horas foi superior para a maioria dos lotes das duas cultivares, com exceção do lote 4 da cultivar Topázio MG 1190. A porcentagem de viabilidade das sementes pelo teste de tetrazólio, quando submetidas ao período de 48 horas de embebição, foi igual ou superior àquelas embebidas por 36 horas. Observa-se, também, que os resultados de viabilidade parecem não ser influenciados pelo teor de água ou qualidade inicial das sementes. De acordo com Dias e Silva (1986), o recomendado é a embebição das sementes por 18 a 24 horas a $30^{\circ} \mathrm{C}$, porém a análise de resultados de pré-testes permite inferir que o tempo indicado é insuficiente para amolecer as sementes, o que dificulta a extração dos embriões. Vieira et al. (1998) relatou que sementes de café, devem ser embebidas em água por um período maior, para que aconteça a ativação suficiente do sistema enzimático, o que melhora e torna o processo de coloração mais rápido, sendo indicados períodos de pré-condicionamento de até 72 horas. Além disto, maior período de embebição facilita a excisão dos embriões. No presente trabalho também foi observado melhor desempenho das sementes embebidas por um período maior (48 horas), além de facilidade na extração do embrião pelo amolecimento do endosperma da semente.

As médias das porcentagens de germinação das duas cultivares estão apresentadas na Tabela 3 . Observa-se que os lotes apresentam diferentes níveis de qualidade e estão dentro dos padrões mínimos de germinação $(70 \%)$ exigidos para a comercialização de sementes de café, de acordo a Portaria n 388 IMA (2000). 
TABELA 2. Médias de viabilidade (\%) e grau de umidade (U\%) de sementes de duas cultivares de café, embebidas em água, em dois períodos ( 24 e 48 h), para extração do embrião.

\begin{tabular}{|c|c|c|c|c|c|c|}
\hline \multicolumn{7}{|c|}{ Cultivares } \\
\hline \multirow{3}{*}{ Lote } & \multicolumn{3}{|c|}{ Mundo Novo 376-4 } & \multicolumn{3}{|c|}{ Topázio MG1190 } \\
\hline & \multirow{2}{*}{$\mathrm{U} \%$} & \multicolumn{2}{|c|}{ Tempo de embebição (horas) } & \multirow{2}{*}{$\mathrm{U} \%$} & \multicolumn{2}{|c|}{ Tempo de embebição (horas) } \\
\hline & & 36 & 48 & & 36 & 48 \\
\hline 1 & 21,0 & $74,25 \mathrm{Bd}^{1}$ & $81,75 \mathrm{Ac}$ & 17,5 & $84,62 \mathrm{Bb}$ & $86,12 \mathrm{Ab}$ \\
\hline 2 & 17,5 & $85,50 \mathrm{Ab}$ & $85,50 \mathrm{Ab}$ & 14,0 & $83,75 \mathrm{Ab}$ & 84,37 Ac \\
\hline 3 & 29,5 & $89,50 \mathrm{Aa}$ & $90,50 \mathrm{Aa}$ & 16,0 & $85,37 \mathrm{Bb}$ & $89,12 \mathrm{Aa}$ \\
\hline 4 & 21,5 & $78,75 \mathrm{Bc}$ & $83,00 \mathrm{Ac}$ & 26,5 & $87,87 \mathrm{Aa}$ & $86,37 \mathrm{Bb}$ \\
\hline
\end{tabular}

${ }^{1}$ Letras maiúsculas nas linhas e minúsculas nas colunas, para cada cultivar, não diferem entre si pelo Teste Scott-Knott no nível nominal de significância de $5 \%$.

TABELA 3. Porcentagem média de germinação de sementes recém-colhidas de quatro lotes de sementes de duas cultivares de café.

\begin{tabular}{ccc}
\hline \multirow{2}{*}{ Lote } & \multicolumn{2}{c}{ Germinação (\%) } \\
\cline { 2 - 3 } & Mundo Novo 376-4 & Topázio MG1190 \\
\hline 1 & $71,00 \mathrm{c}^{1}$ & $82,75 \mathrm{~b}$ \\
2 & $89,00 \mathrm{a}$ & $88,50 \mathrm{a}$ \\
3 & $92,00 \mathrm{a}$ & $91,25 \mathrm{a}$ \\
4 & $74,50 \mathrm{~b}$ & $86,00 \mathrm{~b}$ \\
\hline
\end{tabular}

${ }^{1}$ Médias seguidas de mesma letra minúscula na coluna não diferem entre si pelo Teste Scott-Knott no nível nominal de significância de 5\%.

Os resultados das quatro metodologias utilizadas na realização do teste de tetrazólio foram comparados com os dados do teste de germinação considerando um modelo binomial. Na Tabela 4 estão apresentados apenas valores médios das cultivares submetidas ao teste de germinação e às quatro metodologias de tetrazólio, uma vez que o comportamento das cultivares em relação às metodologias não diferiram entre si. A comparação se dá entre a germinação e cada metodologia do teste de tetrazólio.

É possível observar que as médias de germinação das cultivares são semelhantes aos resultados do teste de tetrazólio quando utilizado a extração do pergaminho com solução de hipoclorito de sódio e com 36 e 48 horas de embebição, diferindo das demais metodologias.

O teste de tetrazólio é realizado sob condições mais favoráveis de ambiente do que as proporcionadas para o teste de germinação, além de ser realizado em menor período de tempo, o que atenua a ação de possíveis fatores adversos, como exemplo microrganismos, não permitindo que esses fatores interfiram na avaliação dos embriões, e segundo França Neto et al. (1998) e Krzyzanowski et al. (1999) são aceitáveis diferenças de até 5\% entre o teste de viabilidade e de germinação. Apesar dos resultados do teste de tetrazólio com uso de hipoclorito de sódio se assemelharem mais com os do teste de germinação, um maior potencial de viabilidade foi observado com a extração manual do pergaminho. Dessa forma, pôde ser observada a interferência negativa do uso de hipoclorito de sódio na realização do teste de tetrazólio.

TABELA 4. Contrastes entre porcentagens de germinação e de viabilidade com utilização de quatro metodologias para a realização do teste de tetrazólio (extração do pergaminho com hipoclorito de sódio ou manual e embebição por 36 e 48 h).

\begin{tabular}{lc}
\hline Método & $\%$ Médias \\
\hline Germinação & 81,4 \\
$\begin{array}{l}\text { Viabilidade (hipoclorito de sódio; } \\
36 \text { h de embebição) }\end{array}$ & $80,0^{\mathrm{ns}}$ \\
$\begin{array}{l}\text { Viabilidade (hipoclorito de sódio; } \\
48 \text { h de embebição) }\end{array}$ & $81,6^{\mathrm{ns}}$ \\
$\begin{array}{l}\text { Viabilidade (manual; 36 h de } \\
\text { embebição) }\end{array}$ & $83,7^{*}$ \\
$\begin{array}{l}\text { Viabilidade (manual; } 48 \text { h de } \\
\text { embebição) }\end{array}$ & $85,4^{*}$ \\
\hline
\end{tabular}

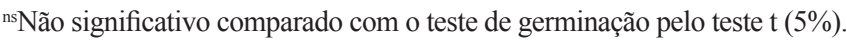

*Significativo comparado com o teste de germinação pelo teste t (5\%). 


\section{CONCLUSÕES}

O uso do hipoclorito de sódio na concentração de $5 \%$ por 6 horas de embebição afeta negativamente os resultados do teste de tetrazólio em semente de café com grau de umidade abaixo de $25 \%$.

O período de embebição de sementes de café por 48 horas na fase de preparo, para a realização do teste de tetrazólio, facilita a extração dos embriões, não afetando os resultados do teste.

\section{REFERÊNCIAS}

BARCELOS, A.F.; PAIVA, P.C. de A.; PEREZ, J.R.O.; SANTOS, V.B.; CARDOSO, R.M. Parâmetros bromatológicos da casca e polpa desidratada de café (Coffea arabica L.) armazenadas em diferentes períodos. Ciência e Agrotecnologia, v.26, n.4, p.780-790. 2002.

BEWLEY, J.D.; BLACK, M. Physiology and Biochemistry of Seeds in Relation to Germination: Viability, Dormancy and Environmental Control. Berlin: Springer-Verlag, 1982. 375p.

BRASIL. Ministério da Agricultura, Pecuária e Abastecimento. Regras para Análise de Sementes. Ministério da Agricultura, Pecuária e Abastecimento. Secretaria de Defesa Agropecuária. Brasília, DF: Mapa/ ACS, 2009. 395p.

COMPANHIA NACIONAL DE ABASTECIMENTO (CONAB). Segundo levantamento de café 2009: maio 2009. Disponível em: <http://www.conab.gov.br/ conabweb/download/safra/2cafe_09.pdf $>$. Acesso em: 30 maio 2009.

DELOUCHE, J.C.; STILL, T.W.; RASPET, M.; LIENHARD, M. O teste de tetrazólio para viabilidade da semente. Brasília, DF: AGIPLAN, 1976. 103p.

DIAS， M.C.L.L.; SILVA, W.R. Determinação da viabilidade de sementes de café através do teste de tetrazólio. Pesquisa Agropecuária Brasileira, v.21, n.11, p.1139-1145. 1986.

ESTRELA，C.; ESTRELA, C.R.A.; BARBIN, E.L.; SPANÓ, J.C.E.; MARCHESAN, M.A.; PÉCORA, J.D. Mecanismo de ação do hipoclorito de sódio. Brazilian Dental Journal, v.13, n.2, p.113-117. 2002.

FERREIRA, D.F. Análise estatística por meio do SISVAR (Sistema para Análise de Variância) para Windows versão 4.0. In: REUNIÃO ANUAL DA REGIÃO BRASILEIRA DA SOCIEDADE INTERNACIONAL DE BIOMETRIA,
45., 2000, São Carlos. Anais... São Carlos: UFSCar, 2000. p.255-258.

FIGUEIREDO, M.P.; LOPES, I.O.; SOUSA, F.G.; MOREIRA, G.R.; SOUSA, L.F.; CRUZ, P.G.; FERREIRA, J.Q. Parâmetros cinéticos da degradação ruminal da casca de café (Coffea arabica, L.) tratada com hidróxido de sódio (NaOH). Ciência Animal Brasileira, v.9, n.1. 2008.

FRANÇANETO, J.B.; KRZYZANOWSKI, F.C.; COSTA, N.P. da. O teste de tetrazólio em sementes de soja. Londrina: EMBRAPA-CNPSo, 1998. 72p. (EMBRAPACNPSo. Documentos, 116).

GUIMARÃES, R.J.; FRAGA, A.C.; MENDES, A.N.G.; CARVALHO, M.L.M.; PASQUAL, M.; CARVALHO, G.R. Efeitos da citocinina, giberelina e remoção do endocarpo na germinação de sementes de cafeeiro (Coffea arabica L.). Ciência e Agrotecnologia, v.22, n.3, p.390396, 1998.

HISE, R. Chlorination. In: DENCE, C.W.; REEVE, D.W. Pulpe bleaching: principles and practice. Atlanta: Tapi, 1996. cap.2, p.241-259.

INSTITUTO MINEIRO DE AGROPECUÁRIA (IMA). Normas e padrões para a produção de sementes básicas e fiscalizadas de café. Portaria $\mathrm{n}^{\mathrm{o}} 388$, de 22 de maio de 2000. Belo Horizonte, 2000. Disponível em: <http:// imanet.ima.mg.gov.br/nova/legis/ portarias.pdf/0388.pdf>. Acesso em: 10 mar. 2009.

KRYZANOWSKI, F.C.; VIEIRA, R.D.; FRANÇA NETO, J.B. Vigor de sementes: conceitos e testes. Londrina: ABRATES, 1999. 218p.

LIMA, J.S. Efeito da reidratação do hipoclorito de sódio na germinação de sementes e emergência de plântulas de cafeeiro. 2008. 68f. Dissertação (Mestrado em Fitotecnia)Universidade Federal de Viçosa, Viçosa, 2008.

MEIRELES, R.C.; ARAUJO, E.F.; REIS, M.S.; SEDIYAMA, C.S.; SAKIYAMA, N.S.; REIS, L.S. Secafé: metodologia para acelerar a germinação das sementes de café. Revista Brasileira de Sementes, v.29, n.3, p.90-96, 2007.

PAMMENTER, N.W.; BERJAK, P. A review of recalcitrant seed physiology in relation to desiccation-tolerance mechanisms. Seed Science Research, v.9, p.13-37, 1999.

PEREIRA, C.E.; PINHO, E.V.R.V.; OLIVEIRA, D.F.; KIKUTI, A.L.P. Determinação de inibidores da germinação no espermoderma de sementes de café (Coffea arabica L.). Revista Brasileira de Sementes, v.24, n.1, p.306-311, 2002. 
R DEVELOPMENT CORE TEAM. R, A language and environment for statistical computing. Vienna: $R$ Foundation for Statistical Computing, 2008. Disponível em: $<\mathrm{http} / / /$ www.R-project.org >. Acesso em: 10 fev. 2009.

SOFIATTI, V.; ARAUJO, E.F.; ARAUJO, R.F.; CARGNIN, A.; REIS, M.S.; SILVA, L.V.B.D. Uso de hipoclorito de sódio para acelerar a emergência das plântulas e o desenvolvimento das mudas de cafeeiro. Bragantia, v.68, n.1, p.233-240, 2009.

VIEIRA, M.G.G.C.; GUIMARÃES, R.M.; PINHO, E.V.R.; GUIMARÃES, R.J.; OLIVEIRA, J.A. Testes rápidos para determinação da viabilidade e da incidência de danos mecânicos em sementes de cafeeiro. Lavras: UFLA, 1998. 34p. (Boletim Agropecuário, 26). 